\title{
The ABCs of incentive-based treatment in health care: a behavior analytic framework to inform research and practice
}

This article was published in the following Dove Press journal:

Psychology Research and Behavior Management

19 March 2014

Number of times this article has been viewed

\section{Steven E Meredith' \\ Brantley $\mathrm{P}$ Jarvis ${ }^{2}$ \\ Bethany R Raiff ${ }^{3}$ \\ Alana M Rojewski \\ Allison Kurti ${ }^{2}$ \\ Rachel N Cassidy ${ }^{2}$ \\ Philip Erb ${ }^{2}$ \\ Jolene R Sy ${ }^{4}$ \\ Jesse Dallery ${ }^{2}$}

'Department of Psychiatry and Behavioral Sciences, The Johns Hopkins University School of Medicine, Baltimore, MD, USA; ${ }^{2}$ Department of Psychology, University of Florida, Gainesville, FL, USA; ${ }^{3}$ Department of Psychology, Rowan University, Glassboro, NJ, USA; ${ }^{4}$ Saint Louis University School of Social Work, St Louis, MO, USA
Correspondence: Steven E Meredith The Johns Hopkins University School of Medicine, 55 10 Nathan Shock Drive, Baltimore, MD 21224, USA

Tel + I 4105502693

Email semeredith@juh.edu

\begin{abstract}
Behavior plays an important role in health promotion. Exercise, smoking cessation, medication adherence, and other healthy behavior can help prevent, or even treat, some diseases. Consequently, interventions that promote healthy behavior have become increasingly common in health care settings. Many of these interventions award incentives contingent upon preventive health-related behavior. Incentive-based interventions vary considerably along several dimensions, including who is targeted in the intervention, which behavior is targeted, and what type of incentive is used. More research on the quantitative and qualitative features of many of these variables is still needed to inform treatment. However, extensive literature on basic and applied behavior analytic research is currently available to help guide the study and practice of incentive-based treatment in health care. In this integrated review, we discuss how behavior analytic research and theory can help treatment providers design and implement incentive-based interventions that promote healthy behavior.
\end{abstract}

Keywords: incentives, contingency management, conditional cash transfer, pay-for-performance, wellness

\section{Introduction}

Behavior and health are inextricably linked. For example, physical inactivity, poor dieting, cigarette smoking, and alcohol consumption are associated with over $75 \%$ of annual health care costs ${ }^{1}$ and nearly $37 \%$ of all deaths in the US., ${ }^{2,3}$ Thus, it is not surprising that treatment providers have become increasingly interested in promoting preventive health-related behavior, such as exercise, healthy dieting, medication adherence, and drug abstinence. In recent years, several types of incentive-based interventions have been developed to promote a range of preventive health-related behavior from pediatric immunizations ${ }^{4}$ to geriatric care. ${ }^{5}$ Conditional cash transfer (CCT) systems are federally run programs that award money to households when health-related conditions are met (eg, attending health care appointments). ${ }^{6}$ Pay for performance (P4P) programs are often administered by insurers and typically provide financial incentives to physicians based on quality-of-care measures (eg, rates of cancer screenings). ${ }^{7}$ Contingency management $(\mathrm{CM})$ programs are used by practitioners to deliver vouchers or prizes to patients contingent on healthy behavior change (eg, drug abstinence) ${ }^{8}$ In addition, a variety of employer-sponsored wellness programs award financial incentives to employees based on utilization of health care services or demonstrations of healthy behavior change (eg, weight loss). ${ }^{9}$

Independent reviews of the health care literature indicate that empirical support for incentive-based interventions is mixed. ${ }^{6,9-14}$ Although some studies have shown that 
these interventions are efficacious, many others have shown that they are not, a finding that several researchers have attributed to differences in how the interventions are designed. ${ }^{15,16}$ Incentive-based interventions can vary with respect to who is targeted in the intervention, which behavior is targeted, what type of incentive is used, and when the incentive is delivered. Understanding the impact that each of these variables has on healthy behavior change can inform the development of more effective interventions. Yet, many of these treatment components have not been systematically investigated in controlled clinical studies. The recent proliferation of incentive-based interventions in health care settings suggests that key stakeholders are unwilling to wait for the scientific community to systematically investigate each variable that is relevant to incentive-based treatment. For instance, federally backed incentive programs are becoming increasingly common around the world. In the US, the Affordable Care Act (March 23, 2010) now encourages employers to adopt wellness programs that incentivize healthy behavior.

If the health care community adopts incentive-based interventions that are uninformed by research or theory, and if these interventions fail, then policymakers may prematurely conclude that incentive-based treatment does not work. Thus, it is important for treatment providers to integrate effective strategies for promoting healthy behavior into incentive-based interventions. When clinical evidence is insufficient to inform the design and implementation of new interventions, researchers and practitioners can turn to an empirically derived conceptual framework for guidance. In this selective review, we discuss how behavior analytic research and theory can be used to inform incentive-based treatments in health care.

\section{Choosing a common conceptual framework}

Although protocols and procedures vary considerably across incentive-based treatments, most interventions share one common feature: the delivery of incentives contingent on health-related behavior. Yet, many different economic and psychological theories have been proposed to account for the same outcomes across CCT, P4P, and other incentive-based interventions. ${ }^{9,17-21}$ A common conceptual framework is needed to facilitate communication and collaboration among researchers and, perhaps more importantly, to help researchers build on existing empirical findings - a scientific practice that is easily lost in multidisciplinary fields. ${ }^{22}$ In addition, a common framework is needed to help practitioners translate empirically derived principles into practice.
Previous research on incentive-based treatments can help researchers and practitioners choose a pragmatic, evidence-based conceptual framework. CM has been the focus of more frequent and systematic empirical investigation than any other incentive-based intervention discussed in the health care literature..$^{23,24}$ It has been shown to promote abstinence from cocaine, ${ }^{25,26}$ opiates,${ }^{27}$ alcohol, ${ }^{28}$ tobacco, ${ }^{29,30}$ marijuana, ${ }^{31}$ and polydrug use. ${ }^{32}$ Indeed, over 30 years of empirical investigations and independent reviews indicate that $\mathrm{CM}$ is one of the most efficacious treatments for drug dependence. ${ }^{13,33,34}$ In addition to promoting drug abstinence, this strategy has been used to promote other health-related behavior, including psychosocial therapy attendance ${ }^{35}$ and medication adherence. ${ }^{36,37}$ Unlike many other incentive-based interventions, the theoretical foundations of $\mathrm{CM}$ are tied to a single conceptual framework: behavior analysis. ${ }^{18,38}$

Behavior analysis involves the study of the behaviorenvironment relationships that influence learning, and it involves the application of learning principles (eg, principles of operant conditioning) in the treatment of behavior problems. Several authors have offered guidelines or recommendations based on behavior analytic research and theory to help inform the design of CM interventions. ${ }^{8,39-46}$ Each of these articles, textbooks, and treatment manuals discusses the importance of a behavior analytic framework to the application of CM. In fact, this empirically derived framework is so central to the design of CM interventions that the efficacy of these interventions is often attributed to the basic behavioral principles on which the treatment approach was founded. $8,23,41,47,48$ Importantly, however, a behavior analytic framework can inform the design of any incentive-based intervention, regardless of whether the intervention is labeled as a CM program, a P4P scheme, a CCT system, or a health contingent wellness program. Indeed, decades of relevant laboratory and clinical research shows that a behavior analytic framework is useful for developing interventions (with or without the use of incentives) that produce clinically meaningful outcomes across a range of socially important problem behavior (eg, see the Journal of Applied Behavior Analysis, 1968-present).

\section{Applying the ABCs of behavior analysis to incentive-based treatment in health care}

A fundamental concept in behavior analysis is the operant contingency. It specifies the functional relationship between an individual's behavior and the antecedents and consequences of that behavior. Thus, when designing an incentive-based intervention, treatment providers must consider, at minimum, 
the three factors that comprise a contingency: antecedents (A), behavior (B), and consequences (C). A evokes B which is modified by $C$. For example, to increase rates of pediatric immunizations, treatment providers could announce the availability of financial incentives for pediatric immunization (A), verify patient compliance with the immunization protocol (B), and deliver incentives contingent on compliance (C). These three factors form an operant contingency, which is sometimes illustrated as follows:

$$
\mathrm{A}: \mathrm{B} \rightarrow \mathrm{C}
$$

Importantly, the contingent relationship between behavior and its consequences is a critical component of an effective incentive-based intervention. When consequences, including incentives, are available noncontingently (ie, not dependent on targeted behavior change), ${ }^{49}$ they do not promote the same treatment outcomes. ${ }^{27,50,51}$ Moreover, a number of other variables can affect whether a consequence will influence behavior, including characteristics of the individual who is engaging in the behavior (eg, his/her current level of motivation), ${ }^{52}$ properties of the behavior itself (eg, how effortful it is to emit the response), ${ }^{53,54}$ quantitative and qualitative features of the consequence (eg, incentive magnitude), ${ }^{32,55,56}$ and temporal features of its delivery (eg, delay between the response and the incentive). ${ }^{57,58}$ Regardless of whether a contingency is arranged by a treatment provider or occurs naturally, each of these variables plays an important role in determining whether a consequence will influence behavior.

\section{Antecedents}

Although much of the research that has been conducted on incentive-based interventions focuses on the consequences of behavior, researchers and practitioners must not ignore the important role that antecedents play in behavior change. An antecedent is a stimulus or event that evokes or inhibits behavior by signaling that a particular consequence is likely to follow a particular response. For example, a No Smoking sign (A) might inhibit cigarette smoking (B), resulting in avoidance of negative financial and/or social consequences (C). In other words, $\mathrm{A}$ is an antecedent that signals that smoking will result in a fine or reprimand. A description of a contingency like this one is called a rule, and, much like a No Smoking sign, a rule can also serve as an antecedent by prompting behavior. ${ }^{59,60}$ Thus, one of the first steps researchers or practitioners must take when incentivizing healthy behavior is to arrange rules to prompt target behavior.
Behavior analytic research and theory suggests that rules are exceptionally useful tools for treatment providers because they can change behavior quicker than direct exposure to incentive-based consequences. ${ }^{61,62}$ In other words, simply notifying an individual that incentives are available for a targeted health-related behavior can prompt healthy behavior before the individual even earns his or her first incentive. Such rules should contain, at minimum, an outline of treatment goals and a description of how incentives will be earned. The more explicit the rules, the more likely the patient will engage in the target behavior. ${ }^{63,64}$ Thus, rules should be communicated effectively in incentive-based interventions. Not surprisingly, research suggests that, when participants in an incentive-based intervention are not informed of the rules, the intervention is less likely to improve targeted treatment outcomes. $^{65}$

Notably, effective communication involves more than just informing patients or practitioners of the rules of an incentive-based intervention. For obvious reasons, rule comprehension is also important. For example, misunderstood contingencies could lead to unhealthy unintended consequences. ${ }^{66}$ To help minimize confusion among participants, treatment providers can explain the rules of an incentive-based intervention in person or over the phone to answer any questions participants might have. In addition, treatment providers can quiz participants about the rules of the intervention. ${ }^{56,67}$

\section{Behavior}

\section{Choosing whose behavior to incentivize}

Practitioners versus groups of practitioners

In many $\mathrm{P} 4 \mathrm{P}$ programs, the administrative challenges associated with incentivizing individual practitioner behavior encourage the delivery of incentives to provider organizations or physician groups. Some research suggests that group-oriented contingencies may benefit participants by promoting social support and lowering treatment costs. ${ }^{68}$ However, interventions that incentivize only the performance of large groups might have limited influence on the behavior of individual group members. ${ }^{69}$

Behavior analytic research and theory suggests that delivering incentives contingent on individual performance has several advantages. When incentives are contingent on individual behavior, the correspondence between targeted behavior and programmed consequences can be very high. For example, the incentives can be delivered every time the behavior occurs and only when the behavior occurs. This correspondence significantly improves the influence that 
consequences have over behavior. ${ }^{70-72}$ In contrast, when incentives are delivered contingent on group performance, correspondence between targeted behavior and incentives may be far lower. This lack of behavior-incentive correspondence might decrease the likelihood that behavior change will occur. ${ }^{73}$ Consequently, behavior analysts tend to prescribe interventions in which programmed consequences are contingent on individual behavior. However, contingencies can be arranged that target both group performance and individual performance. ${ }^{74}$ Interventions that utilize such contingencies could reap the benefits of both group contingencies (eg, increased social support and lower treatment costs) and individual contingencies (eg, increased behavior-incentive correspondence).

\section{Patients versus practitioners}

Although a few studies have demonstrated modest performance improvements with $\mathrm{P} 4 \mathrm{P}$ programs that target individual practitioners, ${ }^{75}$ minimal intervention effects are quite common, and they have led some researchers to conclude that $\mathrm{P} 4 \mathrm{P}$ programs do not work ${ }^{76}$ or that empirical support for programs that target practitioners is, at best, weak. ${ }^{77}$ For example, in a recent systematic review of the P4P literature, Scott et $\mathrm{al}^{14}$ concluded that there is insufficient evidence to support the use of financial incentives to improve the quality of care provided by primary care physicians.

One disadvantage of incentive-based interventions that target practitioners is that participants may seek healthier patients. ${ }^{78,79}$ In other words, practitioners might reject severely ill patients because selection of these patients would lower the practitioners' overall performance and jeopardize their chances of earning performance-based incentives. ${ }^{80,81}$

Another disadvantage of practitioner-based incentive programs is that the incentives may reinforce reporting of health care improvements, even in the absence of any change in care. Such "improvements" may result from more accurate record keeping, 4,82 or they may result from practitioners' attempts to game the incentive-based intervention. ${ }^{83}$ For better or worse, whichever behavior is reinforced is the only one that is guaranteed to increase. Therefore, when incentives reinforce reports of health care improvements, these reports may increase even if they are false.

To maximize behavior-incentive correspondence, behavior analysts typically prescribe interventions that incentivize patient behavior rather than practitioner behavior. Indeed, an increasing number of researchers are calling for patientbased incentives, ${ }^{24,84}$ and several reviews of patient-based P4P programs and health contingent wellness programs suggest that these interventions are effective at promoting healthy behavior. ${ }^{9,85,86}$ Moreover, many patient-based CM programs ${ }^{12}$ and CCT systems ${ }^{6}$ have been successful at promoting a variety of preventive health-related behavior.

\section{Choosing which behavior to incentivize}

\section{Behavior versus behavioral outcomes}

The only way treatment providers can be sure that they are incentivizing healthy behavior is if they can measure it. Thus, when deciding which behavior to incentivize, treatment providers must choose between objectively measurable behavior and behavioral outcomes. For example, if the goal of an intervention is to treat obesity, then providers might choose between incentivizing a behavioral outcome, such as a decrease in weight or body fat percentage, ${ }^{87,88}$ and a behavior, such as dieting or exercising. ${ }^{89,90}$

Directly monitoring behavior can be difficult and costly. When practical constraints prevent treatment providers from observing healthy behavior, behavioral outcomes that are directly linked to healthy behavior may represent a more appropriate target for an incentive-based intervention than alternative behavior that is easy to observe but indirectly related to healthy behavior. For example, to promote drug abstinence, it may be more effective to incentivize biochemical verification of drug abstinence than participation in abstinence-related activities (eg, attending a 12-step meeting). ${ }^{91,92}$ Thus, one important advantage of behavioral outcomes is that they do not require direct monitoring of behavior. However, behavioral outcomes are also associated with several disadvantages. First, treatment providers may have difficulty verifying that changes in behavioral outcomes are produced by changes in healthy behavior. For example, if a behavioral outcome such as weight loss is incentivized, a patient can achieve this goal by taking diet pills or consuming laxatives. Second, targeting behavioral outcomes may increase the likelihood that patients will cheat or game an incentive-based intervention. For example, if the goal of an intervention is to promote physical activity, some behavioral outcomes, such as the number of steps taken per day as indicated by a pedometer, ${ }^{93}$ could reflect activity by the patient's friend, child, or spouse, rather than the patient. Third, some behavioral outcomes can be contaminated. For example, breath carbon monoxide is often measured to assess cigarette smoking. However, second-hand smoke, marijuana smoke, and chronic lung diseases can elevate breath carbon monoxide even if a person has remained abstinent from cigarette smoking. ${ }^{94-96}$ Fourth, some behavioral outcomes may prevent treatment providers from delivering incentives 
close enough in time to the occurrence of healthy behavior. For example, if weight loss is the targeted treatment outcome, an individual may engage in increased physical activity and healthy dieting for several days or weeks before a practitioner sees a substantial decrease in body weight. All of these potential limitations must be considered when choosing a behavioral outcome.

When treatment providers target a specific behavior (eg, physical activity), rather than a behavioral outcome (eg, weight loss), they can be certain that incentives are contingent on clinically desirable behavior. Ideally, target behavior should be the same behavior that treatment providers seek to improve, rather than some ancillary behavior. For example, to promote regular health care checkups, incentivizing attendance at health care appointments ${ }^{97}$ may be more effective than incentivizing enrollment in a psychosocial program that simply encourages health and well-being. ${ }^{98}$

\section{One behavior versus multiple behaviors}

Treatment providers must also decide how many healthy behaviors to target in an incentive-based intervention. For example, some CM interventions have targeted polydrug abuse $^{99}$ rather than just one form of drug abuse. Similarly, CCT programs often target multiple responses concurrently, such as maintaining health insurance coverage and attending dental and medical checkups. ${ }^{100}$ In addition, many P4P programs target multiple quality of care measures simultaneously. ${ }^{101}$ Although providing incentives for multiple targets concurrently can work under some conditions, these programs often fail to produce desired treatment outcomes.

Behavior analytic research and theory suggests that incentivizing more than one behavior might require the use of relatively high magnitude incentives to compete with the reinforcing consequences of multiple unhealthy behaviors. ${ }^{32}$ Moreover, incentivizing multiple target behaviors simultaneously may require participants to emit considerable response effort in order to earn an incentive - perhaps more effort than the incentives are worth. ${ }^{102,103}$ Thus, research suggests that focusing on one behavior at a time ${ }^{104}$ might be the best way to target multiple behaviors. ${ }^{12}$

\section{Performance standards versus improvements}

When choosing which behavior to target, treatment providers must decide whether to incentivize performance standards or performance improvements. Often, treatment goals in incentive-based interventions are predetermined benchmarks or performance standards that are applied to all individuals regardless of baseline performance. If performance standards are set too low, then some individuals may meet or exceed the standards prior to treatment implementation. Such performance standards would not be expected to improve the behavior of these individuals; yet, these individuals would still receive incentives for meeting treatment goals. ${ }^{101}$ If the performance standards are set too high, then they may be out of reach for participants with the worst baseline performance. Even if performance standards prompt behavior change among these participants, individuals whose performance shows the greatest improvements still might not earn any incentives. For example, Rosenthal et $\mathrm{al}^{101}$ found that the greatest improvements in performance among physicians participating in an incentive-based intervention were observed among participants with baseline quality of care measures more than $10 \%$ lower than the performance standards. Yet, these physicians earned only $5 \%$ of the financial incentives that were awarded during the study. In order to maintain treatment gains among individuals who show the greatest improvements in performance, a greater proportion of incentives must be allocated to these participants. Otherwise, they may have no incentive to continue improving their performance, and their behavior will extinguish or return to baseline levels. ${ }^{105}$

Behavior analysts define behavior as a property of an individual. Thus, each individual's ability to engage in targeted behavior should be considered when determining treatment goals. Such an approach to incentivizing healthy behavior entails delivering incentives contingent upon performance improvements (ie, changes in the behavior of each individual relative to his/her baseline performance) ${ }^{106}$ rather than performance standards. Indeed, incentivizing performance improvements allows treatment providers to promote behavior change, even among "hard-to-treat" patients, by offering incentives based on goals that are within reach of each individual. ${ }^{53,107,108}$

\section{Consequences}

\section{Choosing the incentive}

\section{Monetary versus nonmonetary incentives}

Some treatment providers may choose to use non-monetary incentives such as social consequences. Social consequences can promote a variety of behavior, ${ }^{61,109}$ including preventive health-related behavior (eg, weight loss). ${ }^{110,111}$ Social consequences, such as praise for meeting treatment goals, can be delivered by treatment providers or by other members of a patient's social network. ${ }^{112}$ Another form of social consequence - performance feedback - has also been shown to promote a variety of behavior, ${ }^{113,114}$ and it is an important 
feature of many interventions used to promote preventive health-related behavior. ${ }^{115-117}$ Praise and feedback are valuable tools for treatment providers because they can be used to enhance the salience of monetary incentives. Behavior that is followed by a salient consequence is more likely to be influenced by that consequence than a consequence that is not accompanied by any noticeable cues. ${ }^{118}$ Thus, if financial incentives go unnoticed when they are added to or withheld from paychecks, bank accounts, or health insurance bills, they will have little influence over behavior. However, treatment providers who use social consequences when delivering financial incentives can make incentive delivery more salient.

Some incentive-based interventions rely on a variety of other nonmonetary incentives, including consumer products or gift certificates, ${ }^{119}$ access to health-related and recreational facilities, ${ }^{120,121}$ and more flexible work schedules. ${ }^{122}$ One advantage of nonmonetary incentives is that they are often more affordable than monetary incentives. Although treatment providers still have to pay for some nonmonetary incentives, such as food vouchers or bus passes, organizations and businesses may be more willing to donate these items or offer them at discounted rates. ${ }^{123}$

One challenge associated with using nonmonetary incentives is ensuring that they will, in fact, change targeted behavior. Behavior analytic research and theory suggests that the only way to know whether a consequence will increase or decrease behavior is to test it (ie, deliver the incentive following the behavior and observe whether behavior change occurs). When evaluations like these are impractical, preference assessments can help treatment providers determine which incentives patients prefer. For example, patients can rank nonmonetary incentives in order of preference. ${ }^{124,125}$ However, even when individuals indicate their preferences, there is no guarantee that preferred incentives will lead to behavior change. ${ }^{126}$ Moreover, preferences might not persist over time. Patients can become satiated following repeated delivery of the same nonmonetary incentive and, consequently, it can lose its effectiveness. ${ }^{127}$

Many incentive-based interventions use monetary incentives, and behavior analytic research and theory suggests that these incentives have at least one advantage over nonmonetary incentives; that is, the reinforcing efficacy of monetary incentives is less dependent on temporary states of motivation (eg, deprivation or satiation) that influence the value of some nonmonetary incentives. ${ }^{128}$ The use of money to incentivize healthy behavior capitalizes on a preexisting powerful system of conditioned reinforcement. Indeed, there is some evidence that monetary incentives are more effective than nonmonetary incentives at promoting healthy behavior. ${ }^{48,129}$ However, the reinforcing efficacy of money may still depend on relatively chronic states of motivation (eg, limited access to food or other resources due to poverty). Therefore, the value of monetary incentives may be enhanced among individuals who are severely economically disadvantaged, as has been suggested within the context of some CCT programs. ${ }^{130}$

\section{Rewards versus penalties}

Treatment providers must decide whether to provide patients with rewards for meeting specified health goals or impose punitive consequences when patients fail to do so. Although there has been considerable debate on the moral grounds of rewarding versus penalizing behavior, ${ }^{131,132}$ little empirical research has addressed which strategy is more effective when incentivizing healthy behavior. Individuals who support penalty-based incentive schemes cite studies that suggest humans and nonhuman primates are more sensitive to economic losses than gains. ${ }^{133,134}$ Thus, penalizing unhealthy behavior could have a greater impact than rewarding healthy behavior.

Although behavior analytic research and theory suggests that punitive consequences are effective at modifying behavior, there are several disadvantages associated with this treatment approach. ${ }^{135}$ First, basic and applied research has shown that punitive consequences produce side effects, including avoidance of the context in which the punishment occurs and/or the individuals who are administering consequences. ${ }^{136,137}$ Thus, in the context of an incentive-based intervention for healthy behavior, fines or other punitive consequences may have a negative impact on patients' relationships with treatment providers or may cause patients to disengage with treatment. ${ }^{138-140}$ Second, unlike rewards, which are often most effective when delivered intermittently, punitive consequences should be delivered following each occurrence of unhealthy behavior to ensure efficacy. ${ }^{141,142}$ Therefore, punitive consequences may be less practical to administer than rewards. Third, punitive consequences may decrease unhealthy behavior, but they do not teach patients healthy alternatives - rewards are much more useful for shaping new behavior. ${ }^{143}$ Thus, punishment procedures are often most effective when combined with contingencies to reinforce alternative behavior. ${ }^{144}$

\section{Incentive magnitude}

A large body of basic laboratory research shows that higher magnitude reinforcers have greater influence over behavior 
than lower magnitude reinforcers. ${ }^{145,146}$ This finding has been replicated in a number of clinical studies that investigated the effects of incentives on promoting health-related outcomes. ${ }^{32,56,147,148}$ Notably, when determining incentive magnitude, the type of behavior and requirements for earning incentives must be considered. For example, incentive magnitude should be adjusted based on the severity of the health condition or the difficulty (ie, response effort) associated with engaging in the target behavior. Incentive magnitudes may need to be higher when treating individuals with more recent or severe unhealthy behavior. ${ }^{149}$

\section{Choosing when to deliver the incentive}

\section{Incentive delay}

One vital dimension of a consequence that will determine whether it functions as a reinforcer is the temporal proximity between its delivery and the occurrence of the target behavior. In general, the more immediately a reinforcer follows behavior, the more likely it is to strengthen that behavior. ${ }^{72,150-152}$ Indeed, a meta-analysis of CM interventions for substance abuse found that incentive immediacy was associated with larger effect sizes, suggesting that relatively immediate incentives have a greater impact on healthy behavior than more delayed incentives. ${ }^{12}$ In addition, one recent prospective study found that a delay as short as 1 week compromised the influence of a relatively high-magnitude incentive on behavior. ${ }^{57}$ Yet, many incentive-based interventions involve delays of several weeks or months between target behavior and incentive delivery. ${ }^{66,98,153,154}$

\section{Incentive frequency}

The frequency of incentive delivery will depend, in part, on the type of behavior that treatment providers target. Some researchers ${ }^{86}$ have distinguished between two types of target behavior: simple (eg, immunization) and complex (eg, drug abstinence). From a behavior analytic perspective, this distinction can be conceptualized as a difference between behavior that requires only one, or a few, discrete response(s) and behavior that requires repeated responses over an extended duration. Behavior that requires only one response (eg, visiting a clinic to learn the result of a tuberculosis skin test) can be prompted by a relatively small incentive $(\mathrm{eg}, \$ 5) .{ }^{155}$ In contrast, a more "complex" health-related behavior that requires repeated choices over an extended duration (eg, drug abstinence) might require frequent and prolonged reinforcement to establish and maintain behavior change. ${ }^{156}$ Thus, when target behavior involves repeated responding over an extended duration, treatment providers should carefully consider incentive frequency. ${ }^{157,158}$ Indeed, behavior analytic research has shown that there is a quantifiable relationship between behavior and frequency of reinforcement. ${ }^{159}$ Therefore, within the context of an incentive-based intervention, daily incentives would be expected to be more effective at modifying complex behavior than weekly incentives, and weekly incentives would be expected to be more effective than monthly incentives. ${ }^{160}$ As the frequency of incentive delivery continues to decrease, however, the effects of this variable on behavior change may become less noticeable (eg, quarterly versus annual incentives might produce comparable treatment outcomes). ${ }^{161}$

\section{Incentive schedule}

Frequently reinforcing healthy behavior can have very different effects depending on the schedule according to which incentives are delivered. One schedule of reinforcement that has been systematically examined across several clinical studies is as an escalating schedule of reinforcement with a reset contingency. ${ }^{162-165}$ In this schedule, healthy behavior is reinforced with initially small monetary incentives. If the target behavior persists, then incentive magnitude increases upon each occurrence of the behavior. If a patient lapses and engages in unhealthy behavior, then the next occurrence of the healthy behavior will still be reinforced, but the incentive amount resets to the initial, smaller amount. Thus, this schedule interacts dynamically with the behavior of the patient, and it can promote prolonged periods of healthy behavior.

Some incentive schedules rely on intermittent reinforcement to maintain healthy behavior. For example, with a probabilistic schedule, each occurrence of the target behavior results in the immediate opportunity to earn a reward of variable magnitude, but not every opportunity results in a reward (also known as the "fishbowl" method). ${ }^{166}$ Probabilistic schedules have been shown to be as effective as continuous schedules at promoting healthy behavior, ${ }^{167}$ and these schedules of reinforcement can work even with very low magnitude incentives. ${ }^{168}$ However, some research suggests that the probability of earning an incentive should be relatively high in order to be maximally effective at promoting behavior change. ${ }^{70}$

Regardless of which incentive schedule is used to establish healthy behavior, behavior analytic research and theory suggests that target behavior will shift back to unhealthy alternatives when incentives are withdrawn (ie, when incentives are no longer available to compete with the reinforcers produced by unhealthy behavior). Indeed, long-term treatment efficacy is the Achilles' heel of most behavioral, psychosocial, and 
pharmacological interventions designed to improve health. After an intervention is terminated, health benefits observed during treatment often decline. ${ }^{169-171}$ However, within the context of incentive-based treatment, it might be possible to change this pattern by transitioning to the natural contingencies that support healthy behavior or by increasing treatment duration. Once healthy behavior has been established, the frequency of incentive delivery can be gradually reduced to maintain treatment gains. ${ }^{108,172,173}$ This may help practitioners sustain healthy behavior more affordably for longer durations. Indeed, both basic and applied research has shown that, once new behavior is learned, relatively small and infrequent rewards can sustain it over an extended duration. ${ }^{174-176}$

\section{Conclusion}

As discussed throughout this review, findings in the incentive-based treatment literature can be understood in terms of one or more of the elements in the three-term operant contingency: antecedents, behavior, and consequences. For example, the magnitude of financial incentives is important - more is generally better. However, less can work equally well, especially when quantitative, qualitative, and temporal features of other treatment components are optimized (eg, delays to incentives are minimized, frequency of incentive delivery is maximized, rules that specify the contingencies are explicit, etc). Although the experimental procedures employed in most of the incentive-based treatment studies reviewed in this paper preclude any definitive statements regarding the influence of any one of these variables on behavior change, numerous empirical and conceptual papers cited throughout this article suggest that inattention to these variables will compromise incentive-based treatment efficacy. Nevertheless, it is important to note that, relative to other natural sciences, the science of behavior is in a much earlier stage of development. Within the context of incentive-based treatment in health care, many more systematic investigations, including large-scale randomized controlled clinical trials, are still needed to examine various quantitative and qualitative dimensions of each element of the three-term operant contingency.

As the present review has shown, behavior analytic research and a conceptual framework consisting of contemporary operant learning theory ${ }^{177-181}$ and related theories of choice $^{182}$ can help to inform the design and implementation of CM interventions, CCT systems, P4P schemes, health contingent wellness programs, and other incentive-based treatments in health care. In addition, behavior analytic research and theory can be applied to incentive-based interventions in other domains, including education ${ }^{183}$ and industry. ${ }^{184}$ Because behavior analysis is compatible with other economic, psychological, and biological theories, it can help facilitate interdisciplinary communication and collaboration between researchers who are interested in developing and evaluating incentive-based interventions, and it can help researchers build on existing empirical findings. Most importantly, however, behavior analytic research and theory can help practitioners translate empirically derived principles into practical and powerful applications to promote healthy behavior.

\section{Acknowledgments}

Publication of this article was funded by the Open Access Promotion Fund of the Johns Hopkins University Libraries. Financial support for manuscript preparation was provided by the National Institutes of Health grants T32DA007209, R21DA029162, and R01DA023469. The funding sources had no other role in manuscript preparation or in the decision to publish. The authors thank George Bigelow, Kelly Dunn, Maxine Stitzer, and Eric Strain for their helpful feedback on an earlier version of this manuscript.

\section{Disclosure}

The authors report no conflicts of interest in this work.

\section{References}

1. Fisher EB, Fitzgibbon ML, Glasgow RE, et al. Behavior matters. Am J Prev Med. 2011;40:e15-e30.

2. Mokdad AH, Marks JS, Stroup DF, Gerberding JL. Actual causes of death in the United States, 2000. JAMA. 2004;291:1238-1245.

3. Mokdad AH, Marks JS, Stroup DF, Gerberding JL. Correction: Actual causes of death in the united states, 2000. JAMA. 2005;293: 293-294.

4. Fairbrother G, Siegel MJ, Friedman S, Kory PD, Butts GC. Impact of financial incentives on documented immunization rates in the inner city: Results of a randomized controlled trial. Ambul Pediatr. 2001;1: 206-212.

5. Briesacher BA, Field TS, Baril J, Gurwitz JH. Can pay-for-performance take nursing home care to the next level? J Am Geriatr Soc. 2008;56:1937-1939.

6. Ranganathan M, Lagarde M. Promoting healthy behaviours and improving health outcomes in low and middle income countries: A review of the impact of conditional cash transfer programmes. Prev Med. 2012;55:S95-S105.

7. Petersen LA, Woodard LD, Urech T, Daw C, Sookanan S. Does pay-for-performance improve the quality of health care? Ann Intern Med. 2006;145:265-272.

8. Higgins ST, Silverman K, Heil SH. Contingency Management in Substance Abuse Treatment. New York: Guilford Press; 2008.

9. Sutherland K, Christianson JB, Leatherman S. Impact of targeted financial incentives on personal health behavior A review of the literature. Med Care Res Rev. 2008;65:36S-78S.

10. Jha AK, Joynt KE, Orav EJ, Epstein AM. The long-term effect of premier pay for performance on patient outcomes. NEngl J Med. 2012;366: 1606-1615.

11. Lagarde M, Haines A, Palmer N. The impact of conditional cash transfers on health outcomes and use of health services in low and middle income countries. Cochrane Database Syst Rev. 2009;(4):CD008137. 
12. Lussier JP, Heil SH, Mongeon JA, Badger GJ, Higgins ST. A metaanalysis of voucher-based reinforcement therapy for substance use disorders. Addiction. 2006;101:192-203.

13. Prendergast M, Podus D, Finney J, Greenwell L, Roll J. Contingency management for treatment of substance use disorders: A meta-analysis. Addiction. 2006;101:1546-1560.

14. Scott A, Sivey P, Ait Ouakrim D, et al. The effect of financial incentives on the quality of health care provided by primary care physicians. Cochrane Database Syst Rev. 2011;(9):CD008451.

15. Lynagh MC, Sanson-Fisher RW, Bonevski B. What's good for the goose is good for the gander: Guiding principles for the use of financial incentives in health behaviour change. Int J Behav Med. 2013;20:114-120.

16. Van Herck P, De Smedt D, Annemans L, Remmen R, Rosenthal MB, Sermeus W. Systematic review: Effects, design choices, and context of payfor-performance in health care. BMC Health Serv Res. 2010;10:247.

17. Conrad DA, Perry L. Quality-based financial incentives in health care: Can we improve quality by paying for it? Annu Rev Public Health. 2009;30:357-371.

18. Higgins ST, Delaney DD, Budney AJ, et al. A behavioral approach to achieving initial cocaine abstinence. Am J Psychiatry. 1991;148: 1218-1224.

19. Martin A, Suhrcke M, Ogilvie D. Financial incentives to promote active travel: An evidence review and economic framework. Am J Prev Med. 2012;43:e45-e57.

20. McDonald R, Cheraghi-Sohi S, Tickle M, Roland M, Doran T. The impact of incentives on the behaviour and performance of primary care professionals. Report of the National Institute for Health Research Delivery and Organisation Programme. 2010.

21. Volpp KG, Asch DA, Galvin R, Loewenstein G. Redesigning employee health incentives - lessons from behavioral economics. $N$ Engl J Med. 2011;365:388-390.

22. Larsen KR, Voronovich ZA, Cook PF, Pedro LW. Addicted to constructs: Science in reverse? Addiction. 2013;108(9):1532-1533.

23. Higgins ST. Comments on contingency management and conditional cash transfers. Health Econ. 2010;19:1255-1258.

24. Volpp KG, Pauly MV, Loewenstein G, Bangsberg D. P4P4P: An agenda for research on pay-for-performance for patients. Health Aff. 2009;28: 206-214.

25. Higgins ST, Budney AJ, Bickel WK, Foerg FE, Donham R, Badger GJ. Incentives improve outcome in outpatient behavioral treatment of cocaine dependence. Arch Gen Psychiatry. 1994;51:568-576.

26. Stitzer ML, Petry NM, Peirce J. Motivational incentives research in the national drug abuse treatment clinical trials network. J Subst Abuse Treat. 2010;38:S61-S69.

27. Silverman K, Higgins ST, Brooner RK, et al. Sustained cocaine abstinence in methadone maintenance patients through voucher-based reinforcement therapy. Arch Gen Psychiatry. 1996;53:409-415.

28. Petry NM, Martin B, Cooney JL, Kranzler HR. Give them prizes and they will come: Contingency management for treatment of alcohol dependence. J Consult Clin Psychol. 2000;68:250-257.

29. Higgins ST, Washio Y, Heil SH, et al. Financial incentives for smoking cessation among pregnant and newly postpartum women. Prev Med. 2012;55:S33-S40.

30. Stitzer ML, Rand CS, Bigelow GE, Mead AM. Contingent payment procedures for smoking reduction and cessation. J Appl Behav Anal. 1986;19:197-202.

31. Budney AJ, Higgins ST, Radonovich KJ, Novy PL. Adding voucher-based incentives to coping skills and motivational enhancement improves outcomes during treatment for marijuana dependence. J Consult Clin Psychol. 2000;68:1051-1061.

32. Dallery J, Silverman K, Chutuape MA, Bigelow GE, Stitzer ML. Voucher-based reinforcement of opiate plus cocaine abstinence in treatment-resistant methadone patients: Effects of reinforcer magnitude. Exp Clin Psychopharmacol. 2001;9:317-325.

33. Dutra L, Stathopoulou G, Basden SL, Leyro TM, Powers MB, Otto MW A meta-analytic review of psychosocial interventions for substance use disorders. Am J Psychiatry. 2008;165:179-187.
34. McGovern MP, Carroll KM. Evidence-based practices for substance use disorders. Psychiatr Clin North Am. 2003;26:991-1010.

35. Rhodes GL, Saules KK, Helmus TC, et al. Improving on-time counseling attendance in a methadone treatment program: A contingency management approach. Am J Drug Alcohol Abuse. 2003;29: 759-773.

36. Preston KL, Silverman K, Umbricht A, DeJesus A, Montoya ID, Schuster CR. Improvement in naltrexone treatment compliance with contingency management. Drug Alcohol Depend. 1999;54:127-135.

37. Rosen MI, Dieckhaus K, McMahon TJ, et al. Improved adherence with contingency management. AIDS Patient Care STDS. 2007;21: 30-40.

38. Stitzer ML, Bigelow GE, Liebson I. Reducing drug use among methadone maintenance clients: Contingent reinforcement for morphine-free urines. Addict Behav. 1980;5:333-340.

39. Bigelow GE, Silverman K. Theoretical and empirical foundations of contingency management treatments for drug abuse. In: Higgins ST, Silverman K, editors. Motivating Behavior Change Among Illicit-Drug Abusers: Research on Contingency Management Interventions. Washington, DC: American Psychological Association; 1999:15-31.

40. Budney A, Higgins S. A community reinforcement plus vouchers approach: Treating cocaine addiction (NIDA publication no 98-4309 ed) Rockville, Maryland: NIDA. 1998. Available from http://archives. drugabuse.gov/pdf/CRA.pdf. Accessed February 26, 2014.

41. Dallery J, Meredith SE, Budney AJ. Contingency management in the substance abuse treatment clinic. In: Walters ST, Rotgers F, editors. Treating Substance Abuse. 3rd ed. New York: Guilford; 2012:81.

42. Kellogg S, Stitzer M, Petry N, Kreek M. Motivational incentives: Foundations and principles. Promoting Awareness of Motivational Incentive - An awareness Campaign. 2007. Available from http:// www.bettertxoutcomes.org/bettertxoutcomes/PDF/Kellog-Stitzer.pdf. Accessed February 26, 2014.

43. McIntosh L. Contingency Management Part 1: An Evidence-Based Approach to Positive Change. Portland: Northwest Frontier Addiction Technology Transfer Center; 2012. Available from: http://www. attcnetwork.org/find/news/attcnews/epubs/addmsg/documents/AMJanuary2012-Part1-ContingencyManagement.pdf. Accessed.

44. Petry NM. Contingency Management for Substance Abuse Treatment: A Guide to Implementing this Evidence-Based Practice. Routledge, New York, NY; 2012.

45. Petry NM. A comprehensive guide to the application of contingency management procedures in clinical settings. Drug Alcohol Depend. 2000;58:9-25.

46. Stitzer M, Petry N. Contingency management for treatment of substance abuse. Annu Rev Clin Psychol. 2006;2:411-434

47. Dallery J, Raiff BR. Contingency management in the 21 st century: Technological innovations to promote smoking cessation. Subst Use Misuse. 2011;46:10-22.

48. Stoops WW, Lile JA, Rush CR. Monetary alternative reinforcers more effectively decrease intranasal cocaine choice than food alternative reinforcers. Pharmacol Biochem Behav. 2010;95:187-191.

49. Carr JE, Coriaty S, Wilder DA, et al. A review of "noncontingent" reinforcement as treatment for the aberrant behavior of individuals with developmental disabilities. Res Dev Disabil. 2000;21:377-391.

50. Higgins ST, Wong CJ, Badger GJ, Ogden DE, Dantona RL. Contingent reinforcement increases cocaine abstinence during outpatient treatment and 1 year of follow-up. J Consult Clin Psychol. 2000;68: 64-72.

51. Jones HE, Johnson RE, Bigelow GE, Silverman K, Mudric T, Strain EC. Safety and efficacy of L-tryptophan and behavioral incentives for treatment of cocaine dependence: A randomized clinical trial. Am J Addiction. 2004;13:421-437.

52. Iwata BA, Smith RG, Michael J. Current research on the influence of establishing operations on behavior in applied settings. J Appl Behav Anal. 2000;33:411-418.

53. Lamb RJ, Morral AR, Kirby KC, Iguchi M, Galbicka G. Shaping smoking cessation using percentile schedules. Drug Alcohol Depend. 2004;76:247-259. 
54. Friman PC, Poling A. Making life easier with effort: Basic findings and applied research on response effort. J Appl Behav Anal. 1995;28: 583-590.

55. Hoch H, McComas JJ, Johnson L, Faranda N, Guenther SL. The effects of magnitude and quality of reinforcement on choice responding during play activities. J Appl Behav Anal. 2002;35:171-181.

56. Silverman K, Chutuape MA, Bigelow GE, Stitzer ML. Voucher-based reinforcement of cocaine abstinence in treatment-resistant methadone patients: Effects of reinforcement magnitude. Psychopharmacol. 1999;146:128-138.

57. Packer RR, Howell DN, McPherson S, Roll JM. Investigating reinforcer magnitude and reinforcer delay: A contingency management analog study. Exp Clin Psychopharmacol. 2012;20:287-292.

58. Critchfield TS, Kollins SH. Temporal discounting: Basic research and the analysis of socially important behavior. J Appl Behav Anal. 2001;34:101-122.

59. Ayllon T, Azrin NH. Reinforcement and instructions with mental patients. J Exp Anal Behav. 1964;7:327-331.

60. Hayes SC, Zettle RD, Rosenfarb I. Rule-following. In: Hayes SC, editor. Rule-governed behavior. New York: Plenum;1989:191-220.

61. Crowell CR, Anderson DC, Abel DM, Sergio JP. Task clarification, performance feedback, and social praise: Procedures for improving the customer service of bank tellers. J Appl Behav Anal. 1988;21:65-71.

62. Huber V. The interplay of goals and promises of pay-for-performance on individual and group performance: An operant interpretation. J Organ Behav Manage. 1986;7:45-64.

63. Locke EA, Brian JF. The directing function of goals in task performance. J Organ Behav Manage. 1968;4:35-42.

64. Mawhinney TC, Ford JD. The path goal theory of leader effectiveness: An operant interpretation. Acad Manage Rev. 1977;2:398-411.

65. Hillman AL, Ripley K, Goldfarb N, Weiner J, Nuamah I, Lusk E. The use of physician financial incentives and feedback to improve pediatric preventive care in medicaid managed care. Pediatrics. 1999;104: 931-935.

66. Morris SS, Olinto P, Flores R, Nilson EA, Figueiró AC. Conditional cash transfers are associated with a small reduction in the rate of weight gain of preschool children in northeast brazil. J Nutr. 2004;134: 2336-2341.

67. Festinger DS, Dugosh KL, Croft JR, Arabia PL, Marlowe DB. Corrected feedback: A procedure to enhance recall of informed consent to research among substance abusing offenders. Ethics Behav. 2010;20: 387-399.

68. Meredith SE, Dallery J. Investigating group contingencies to promote brief abstinence from cigarette smoking. Exp Clin Psychopharmacol. 2013;21:144-154.

69. Bokhour BG, Burgess JF Jr, Hook JM, et al. Incentive implementation in physician practices: A qualitative study of practice executive perspectives on pay for performance. Med Care Res Rev. 2006;63: $73 \mathrm{~S}-95 \mathrm{~S}$.

70. Ghitza UE, Epstein DH, Schmittner J, Vahabzadeh M, Lin J, Preston KL. Effect of reinforcement probability and prize size on cocaine and heroin abstinence in prize-based contingency management. J Appl Behav Anal. 2008;41:539-549.

71. Martens BK, Ardoin SP, Hilt AM, Lannie AL, Panahon CJ, Wolfe LA. Sensitivity of children's behavior to probabilistic reward: Effects of a decreasing-ratio lottery system on math performance. J Appl Behav Anal. 2002;35:403-406.

72. Lattal KA. Delayed reinforcement of operant behavior. $J$ Exp Anal Behav. 2010;93:129-139.

73. Kirby KC, Kerwin ME, Carpenedo CM, Rosenwasser BJ, Gardner RS. Interdependent group contingency management for cocainedependent methadone maintenance patients. J Appl Behav Anal. 2008;41:579-595.

74. Meredith SE, Grabinski MJ, Dallery J. Internet-based group contingency management to promote abstinence from cigarette smoking: A feasibility study. Drug Alcohol Depend. 2011;118:23-30.
75. Vandrey R, Stitzer ML, Acquavita SP, Quinn-Stabile P. Pay-for-performance in a community substance abuse clinic. $J$ Subst Abuse Treat. 2011:41:193-200.

76. Jha AK. Time to get serious about pay for performance. JAMA. 2013;309:347-348

77. Rosenthal MB, Frank RG. What is the empirical basis for paying for quality in health care? Med Care Res Rev. 2006;63:135-157.

78. Christianson JB, Leatherman S, Sutherland K. Lessons from evaluations of purchaser pay-for-performance programs a review of the evidence. Med Care Res Rev. 2008;65:5S-35S.

79. Doran T, Fullwood C, Gravelle H, et al. Pay-for-performance programs in family practices in the united kingdom. $N$ Engl $J$ Med. 2006;355:375-384.

80. Shen Y. Selection incentives in a Performance-Based contracting system. Health Serv Res. 2003;38:535-552.

81. Chang RE, Lin SP, Aron DC. A pay-for-performance program in Taiwan improved care for some diabetes patients, but doctors may have excluded sicker ones. Health Aff (Millwood). 2012;31: 93-102.

82. Fairbrother G, Hanson KL, Friedman S, Butts GC. The impact of physician bonuses, enhanced fees, and feedback on childhood immunization coverage rates. Am J Public Health. 1999;89: 171-175.

83. Lu M. Separating the true effect from gaming in Incentive-Based contracts in health care. J Econ Manage Strat. 1999;8:383-431.

84. Sindelar JL. Paying for performance: the power of incentives over habits. Health Econ. 2008;17:449-451.

85. Giuffrida A, Torgerson DJ. Should we pay the patient? Review of financial incentives to enhance patient compliance. BMJ. 1997;315:703-707.

86. Kane RL, Johnson PE, Town RJ, Butler M. A structured review of the effect of economic incentives on consumers' preventive behavior. $\mathrm{Am}$ J Prev Med. 2004;27:327-352.

87. Jeffery RW, Gerber WM, Rosenthal BS, Lindquist RA. Monetary contracts in weight control: effectiveness of group and individual contracts of varying size. J Consult Clin Psychol. 1983;51: 242-248

88. John LK, Loewenstein G, Troxel AB, Norton L, Fassbender JE, Volpp KG. Financial incentives for extended weight loss: a randomized, controlled trial. J Gen Intern Med. 2011;26:621-626.

89. Charness G, Gneezy U. Incentives to exercise. Econometrica. 2009;77:909-931.

90. De Luca RV, Holborn SW. Effects of a variable-ratio reinforcement schedule with changing criteria on exercise in obese and nonobese boys. J Appl Behav Anal. 1992;25:671-679.

91. Finkelstein EA, Brown DS, Brown DR, Buchner DM. A randomized study of financial incentives to increase physical activity among sedentary older adults. Prev Med. 2008;47:182-187.

92. Sato S, Nishimura K, Koyama H, et al. Optimal cutoff level of breath carbon monoxide for assessing smoking status in patients with asthma and COPD. Chestl. 2003;124:1749-1754.

93. Wallace LA. Carbon monoxide in air and breath of employees in an underground office. J Air Pollut Control Assoc. 1983;33:678-682.

94. Wu T, Tashkin DP, Djahed B, Rose JE. Pulmonary hazards of smoking marijuana as compared with tobacco. N Engl J Med. 1988;318: 347-351.

95. Attanasio O, Mesnard A. The impact of a conditional cash transfer programme on consumption in Colombia. Fiscal Studies. 2006;27: 421-442.

96. Galasso E. Alleviating extreme poverty in Chile: The short term effects of Chile Solidario. Estudios de Economía. 2011;38:101-127.

97. Iguchi MY, Lamb RJ, Belding MA, Platt JJ, Husband SD, Morral AR. Contingent reinforcement of group participation versus abstinence in a methadone maintenance program. Exp Clin Psychopharmacol. 1996;4: 315-321.

98. Petry NM, Alessi SM, Carroll KM, et al. Contingency management treatments: Reinforcing abstinence versus adherence with goal-related activities. J Consult Clin Psychol. 2006;74:592-601. 
99. Downey KK, Helmus TC, Schuster CR. Treatment of heroin-dependent poly-drug abusers with contingency management and buprenorphine maintenance. Exp Clin Psychopharmacol. 2000;8:176-184.

100. Riccio J, Dechausay N, Greenberg D, Miller C, Rucks Z, Verma N. Toward Reduced Poverty Across Generations: Early Findings from New York City's Conditional Cash Transfer Program. New York: MDRC; 2010. Available from: http://www.mdrc.org/sites/default/files/full_588. pdf. Accessed.

101. Rosenthal MB, Frank RG, Li Z, Epstein AM. Early experience with pay-for-performance. JAMA. 2005;294:1788-1793.

102. Roane HS. On the applied use of progressive-ration schedules of reinforcement. J Appl Behav Anal. 2008;41:155-161.

103. Weissman NW, Crossman EK. A comparison of two types of extinction following fixed-ratio training. J Exp Anal Behav. 1966;9:41-46.

104. Ward P, Carnes M. Effects of posting self-set goals on collegiate football players' skill execution during practice and games. $J$ Appl Behav Anal. 2002;35:1-12.

105. Lerman DC, Iwata BA. Developing a technology for the use of operant extinction in clinical settings: An examination of basic and applied research. J Appl Behav Anal. 1996;29:345-382.

106. Hartmann DP, Hall RV. The changing criterion design. J Appl Behav Anal. 1976;9:527-532.

107. Lamb RJ, Kirby KC, Morral AR, Galbicka G, Iguchi MY. Shaping smoking cessation in hard-to-treat smokers. J Consult Clin Psychol. 2010;78:62-71.

108. Preston KL, Umbricht A, Wong CJ, Epstein DH. Shaping cocaine abstinence by successive approximation. J Consult Clin Psychol. 2001;69:643-654.

109. Hanley GP, Iwata BA, McCord BE. Functional analysis of problem behavior: A review. J Appl Behav Anal. 2003;36:147-185.

110. Black DR, Gleser LJ, Kooyers KJ. A meta-analytic evaluation of couples weight-loss programs. Health Psychol. 1990;9:330-347.

111. Wing RR, Jeffery RW. Benefits of recruiting participants with friends and increasing social support for weight loss and maintenance. J Consult Clin Psychol. 1999;67:132-138.

112. Donatelle RJ, Prows SL, Champeau D, Hudson D. Randomised controlled trial using social support and financial incentives for high risk pregnant smokers: Significant other supporter (SOS) program. Tob Control. 2000;9 Suppl 3:III67-III69.

113. Codding RS, Feinberg AB, Dunn EK, Pace GM. Effects of immediate performance feedback on implementation of behavior support plans. J Appl Behav Anal. 2005;38:205-219.

114. Komaki J, Heinzmann AT, Lawson L. Effect of training and feedback: Component analysis of a behavioral safety program. J Appl Psychol. 1980;65:261-270.

115. Barton MB, Schoenbaum SC. Improving influenza vaccination performance in an HMO setting: the use of computer-generated reminders and peer comparison feedback. Am J Public Health. 1990;80: 534-536.

116. Russos S, Hovell MF, Keating K, et al. Clinician compliance with primary prevention of tobacco use: The impact of social contingencies. Prev Med. 1997;26:44-52.

117. Tromp M, Hulscher M, Bleeker-Rovers CP, et al. The role of nurses in the recognition and treatment of patients with sepsis in the emergency department: A prospective before-and-after intervention study. Int J Nurs Stud. 2010;47:1464-1473.

118. Zifferblatt SM. Increasing patient compliance through the applied analysis of behavior. Prev Med. 1975;4:173-182.

119. Deren S, Stephens R, Davis WR, Feucht TE, Tortu S. The impact of providing incentives for attendance at AIDS prevention sessions. Public Health Rep. 1994;109:548-554.

120. Mayer JA, Kellogg MC. Promoting mammography appointment making. J Behav Med. 1989;12:605-611.

121. Harland J, White M, Drinkwater C, Chinn D, Farr L, Howel D. The Newcastle exercise project: A randomised controlled trial of methods to promote physical activity in primary care. BMJ. 1999;319: 828-832.
122. Iwata BA, Bailey JS, Brown KM, Foshee TJ, Alpern M. A performance-based lottery to improve residential care and training by institutional staff. J Appl Behav Anal. 1976;9:417-431.

123. Amass L, Kamien J. A tale of two cities: Financing two voucher programs for substance abusers through community donations. Exp Clin Psychopharmacol. 2004;12:147-155.

124. Amass L, Bickel WK, Crean JP, Higgins ST, Badger GJ. Preferences for clinic privileges, retail items and social activities in an outpatient buprenorphine treatment program. J Subst Abuse Treat. 1996;13:43-49.

125. Chutuape MA, Silverman K, Stitzer ML. Survey assessment of methadone treatment services as reinforcers. Am J Drug Alcohol Abuse. 1998;24:1-16.

126. Northup J. Further evaluation of the accuracy of reinforcer surveys: a systematic replication. J Appl Behav Anal. 2000;33:335-338.

127. Lindberg JS, Iwata BA, Roscoe EM, Worsdell AS, Hanley GP. Treatment efficacy of noncontingent reinforcement during brief and extended application. J Appl Behav Anal. 2003;36:1-19.

128. Kazdin AE, Bootzin RR. The token economy: An evaluative review. J Appl Behav Anal. 1972;5:343-372.

129. Vandrey R, Bigelow GE, Stitzer ML. Contingency management in cocaine abusers: A dose-effect comparison of goods-based versus cash-based incentives. Exp Clin Psychopharmacol. 2007;15: 338-343.

130. Maluccio J, Flores R. Impact Evaluation of a Conditional Cash Transfer Program: The Nicaraguan Red De Protección Social. Washington, DC: International Food Policy Research Institute; 2005.

131. Ashcroft RE. Personal financial incentives in health promotion: where do they fit in an ethic of autonomy? Health Expectations. 2011;14: 191-200.

132. Madison KM, Volpp KG, Halpern SD. The law, policy, and ethics of employers' use of financial incentives to improve health. J Law Med Ethics. 2011;39:450-468.

133. Kahneman D, Tversky A. Prospect theory: An analysis of decision under risk. Econometrica. 1979;47:263-291.

134. Lakshminarayanan VR, Chen MK, Santos LR. The evolution of decision-making under risk: Framing effects in monkey risk preferences. J Exp Soc Psychol. 2011;47:689-693.

135. Lerman DC, Vorndran CM. On the status of knowledge for using punishment implications for treating behavior disorders. J Appl Behav Anal. 2002;35:431-464.

136. Azrin N, Hutchinson R, McLaughlin R. The opportunity for aggression as an operant reinforcer during aversive stimulation. J Exp Anal Behav. 1965;8:171-180.

137. Powell J, Azrin N. The effects of shock as a punisher for cigarette smoking. J Appl Behav Anal. 1968;1:63-71.

138. Mavis BE, Stöffelmayr BE. Multidimensional evaluation of monetary incentive strategies for weight control. Psychol Rec. 1994;44: 239-252.

139. Iguchi MY, Stitzer ML, Bigelow GE, Liebson IA. Contingency management in methadone maintenance: Effects of reinforcing and aversive consequences on illicit polydrug use. Drug Alcohol Depend. 1988;22:1-7

140. Roll JM, Howard JT. The relative contribution of economic valence to contingency management efficacy: a pilot study. J Appl Behav Anal. 2008;41:629-633.

141. Azrin N, Holz W, Hake D. Fixed-ratio punishment. J Exp Anal Behav. 1963;6:141-148.

142. Lerman DC, Iwata BA, Shore BA, DeLeon IG. Effects of intermittent punishment on self-injurious behavior: An evaluation of schedule thinning. J Appl Behav Anal. 1997;30:187-201.

143. Martin G, Pear J. Behavior Modification: What it is and How to Do It. 9th ed. Boston: Pearson Education/Allyn and Bacon; 2011.

144. Thompson RH, Iwata BA, Conners J, Roscoe EM. Effects of reinforcement for alternative behavior during punishment of self-injury. $J \mathrm{Appl}$ Behav Anal. 1999;32:317-328. 
145. Catania AC. Concurrent performances: A baseline for the study of reinforcement magnitude. J Exp Anal Behav. 1963;6:299-300.

146. Neuringer AJ. Effects of reinforcement magnitude on choice and rate of responding. J Exp Anal Behav. 1967;10:417-424.

147. Fernald LC, Gertler PJ, Neufeld LM. Role of cash in conditional cash transfer programmes for child health, growth, and development: An analysis of Mexico's Oportunidades. Lancet. 2008;371:828-837.

148. Higgins ST, Heil SH, Dantona R, Donham R, Matthews M, Badger GJ. Effects of varying the monetary value of voucher-based incentives on abstinence achieved during and following treatment among cocainedependent outpatients. Addiction. 2007;102:271-281.

149. Petry NM, Tedford J, Austin M, Nich C, Carroll KM, Rounsaville BJ. Prize reinforcement contingency management for treating cocaine users: How low can we go, and with whom? Addiction. 2004;99: 349-360.

150. Ferster C, Hammer C. Variables determining the effects of delay in reinforcement. J Exp Anal Behav. 1965;8:243-254.

151. Ferster CB. Sustained behavior under delayed reinforcement. J Exp Psychol. 1953;45:218-224.

152. Sy JR, Vollmer TR. Discrimination acquisition in children with developmental disabilities under immediate and delayed reinforcement. J Appl Behav Anal. 2012;45:667-684.

153. Grady KE, Lemkau JP, Lee NR, Caddell C. Enhancing mammography referral in primary care. Prev Med. 1997;26:791-800.

154. Hillman AL, Ripley K, Goldfarb N, Nuamah I, Weiner J, Lusk E. Physician financial incentives and feedback: Failure to increase cancer screening in medicaid managed care. Am J Public Health. 1998;88: 1699-1701.

155. Malotte CK, Rhodes F, Mais KE. Tuberculosis screening and compliance with return for skin test reading among active drug users. Am J Public Health. 1998;88:792-796.

156. Silverman K, Svikis D, Robles E, Stitzer ML, Bigelow GE. A reinforcement-based therapeutic workplace for the treatment of drug abuse: Six-month abstinence outcomes. Exp Clin Psychopharmacol. 2001;9:14-23.

157. Higgins ST, Budney AJ, Bickel WK. Applying behavioral concepts and principles to the treatment of cocaine dependence. Drug Alcohol Depend. 1994;34:87-97.

158. Silverman K, DeFulio A, Sigurdsson SO. Maintenance of reinforcement to address the chronic nature of drug addiction. Prev Med. 2012;55:S46-S53.

159. Herrnstein RJ. On the law of effect. J Exp Anal Behav. 1970;13: 243-266.

160. Chutuape MA, Silverman K, Stitzer ML. Effects of urine testing frequency on outcome in a methadone take-home contingency program. Drug Alcohol Depend. 2001;62:69-76.

161. Chung S, Palaniappan L, Wong E, Rubin H, Luft H. Does the frequency of Pay-for-Performance payment matter? - Experience from a randomized trial. Health Serv Res. 2010;45:553-564.

162. Roll JM, Higgins ST, Badger GJ. An experimental comparison of three different schedules of reinforcement of drug abstinence using cigarette smoking as an exemplar. J Appl Behav Anal. 1996;29:495-504.

163. Roll JM, Higgins ST. A within-subject comparison of three different schedules of reinforcement of drug abstinence using cigarette smoking as an exemplar. Drug Alcohol Depend. 2000;58:103-109.

164. Roll JM, Shoptaw S. Contingency management: Schedule effects. Psychiatry Res. 2006;144:91-93.

Psychology Research and Behavior Management

\section{Publish your work in this journal}

Psychology Research and Behavior Management is an international, peerreviewed, open access journal focusing on the science of psychology and its application in behavior management to develop improved outcomes in the clinical, educational, sports and business arenas. Specific topics covered include: Neuroscience, memory \& decision making; Behavior
165. Romanowich P, Lamb RJ. Effects of escalating and descending schedules of incentives on cigarette smoking in smokers without plans to quit. J Appl Behav Anal. 2010;43:357-367.

166. Petry NM, Simcic F Jr. Recent advances in the dissemination of contingency management techniques: clinical and research perspectives. J Subst Abuse Treat. 2002;23:81-86.

167. Petry NM, Alessi SM, Marx J, Austin M, Tardif M. Vouchers versus prizes: contingency management treatment of substance abusers in community settings. J Consult Clin Psychol. 2005;73:1005-1014.

168. Lott DC, Jencius S. Effectiveness of very low-cost contingency management in a community adolescent treatment program. Drug Alcohol Depend. 2009;102:162-165.

169. Etter JF, Stapleton JA. Nicotine replacement therapy for long-term smoking cessation: a meta-analysis. Tob Control. 2006;15(4): 280-285.

170. Jeffery RW, Drewnowski A, Epstein LH, et al. Long-term maintenance of weight loss: Current status. Health Psychol. 2000;19(Suppl 1): $5-16$.

171. Norris SL, Lau J, Smith SJ, Schmid CH, Engelgau MM. Selfmanagement education for adults with type 2 diabetes: A metaanalysis of the effect on glycemic control. Diabetes Care. 2002;25(7): 1159-1171.

172. Kirby KC, Marlowe DB, Festinger DS, Lamb RJ, Platt JJ. Schedule of voucher delivery influences initiation of cocaine abstinence. J Consult Clin Psychol. 1998;66(5):761-767.

173. Preston KL, Umbricht A, Epstein DH. Abstinence reinforcement maintenance contingency and one-year follow-up. Drug Alcohol Depend. 2002;67(2):125-137.

174. Baer RA, Blount RL, Detrich R, Stokes TF. Using intermittent reinforcement to program maintenance of verbal/nonverbal correspondence. J Appl Behav Anal. 1987;20:179-184.

175. Ferster CB, Skinner B. Schedules of Reinforcement. New York: Appleton-Century-Crofts; 1957.

176. Freeland JT, Noell GH. Programming for maintenance: An investigation of delayed intermittent reinforcement and common stimuli to create indiscriminable contingencies. J Behav Educ. 2002;11:5-18.

177. Baum WM. Understanding Behaviorism: Behavior, Culture, and Evolution. 2nd ed. Malden, MA: Blackwell Pub; 2005.

178. Catania AC. Learning. 5th ed. Cornwall-on-Hudson, NY: Sloan Pub; 2013.

179. Cheney CD, Pierce WD. Behavior Analysis and Learning. 5th ed. New York: Psychology Press; 2013.

180. Chiesa M. Radical Behaviorism: The Philosophy and the Science. Boston: Authors Cooperative; 1994.

181. Skinner BF. Verbal Behavior. Appleton-Century-Crofts New York; 1957.

182. Mazur JE. Estimation of indifference points with an adjusting-delay procedure. J Exp Anal Behav. 1988;49(1):37-47.

183. Fryer RG Jr. Financial incentives and student achievement: Evidence from randomized trials. The Quarterly Journal of Economics. 2011;126:1755-1798.

184. Bucklin BR, Dickinson AM. Individual monetary incentives: a review of different types of arrangements between performance and pay. J Organ Behav Manage. 2001;21:45-137.

modification \& management; Clinical applications; Business \& sports performance management; Social and developmental studies; Animal studies. The manuscript management system is completely online and includes a quick and fair peer-review system. Visit http://www.dovepress. com/testimonials.php to read real quotes from published authors. 